\title{
A Comparative Analysis of Clinical Characteristics and Laboratory Findings of COVID-19 between Intensive Care Unit and Non-Intensive Care Unit Pediatric Patients: A Multicenter, Retrospective, Observational Study from Iranian Network for Research in Viral Diseases (INRVD)
}

\section{Alireza Fahimzad}

Shahid Beheshti University of Medical Sciences

Iraj Sedighi

Hamadan University of Medical Sciences

Neda Pak

Tehran University of Medical Sciences

Mitra Khalili

Mofid Children Hospital, Shahid Beheshti University of Medical Sciences

Mohammad Farahmand

Tehran University of Medical Sciences

Mohammad Reza Shokrollahi

Qom University of Medical Sciences

Hosein Heydari

Qom University of Medical Sciences

Zahra Movahedi

Qom University of Medical Sciences

Anahita Sanaei Dashti

Shiraz University of Medical Sciences

Fatemeh Cheraghali

Golestan University of Medical Sciences

Ahmad Shamsizadeh

Aboozar Children Hospital, Ahvaz Jundishapur University of Medical Sciences

Mohammadreza Mirkarimi

Aboozar Children Hospital, Ahvaz Jundishapur University of Medical Sciences

Mohsen Alisamir

Aboozar Children Hospital, Ahvaz Jundishapur University of Medical Sciences

Houman Hashemian 
Guilan University of Medical Sciences

Jafar Soltani

Kurdistan University of Medical Sciences

Ali Hosseininasab

Kerman University of Medical Sciences

Abdolkarim Hamedi

Mashhad University of Medical Sciences

Mohammad Sadegh Rezai

Mazandaran University of Medical Sciences

Shirin Sayyahfar

Iran University of Medical Sciences

Manijeh Kahbazi

Arak University of Medical Sciences

Aliakbar Abedini

Tabriz University of Medical Sciences

Afsaneh Akhondzadeh

Arak University of Medical Sciences

Hamid Reza Sherkatolabbasieh

Lorestan University of medical Sciences

Ali Akbar Razlansari

Lorestan University of medical Sciences

Mina Alibeik

Mofid Children Hospital, Shahid Beheshti University of Medical Sciences

\section{Soheil Omid Malayeri}

Islamic Azad University

\section{Zohreh Shalchi}

Hamadan University of Medical Sciences

\section{Ali Shahabinezhad}

Imam Khomeini Hospital, Tehran University of Medical Sciences

Parinaz Khalkhali Asl

Golestsn University of Medical Sciences

Fatemeh Nafe Monfared

Tehran University of Medical Sciences

\section{Shiva Maleki}

Tarbiat Modares University

Rezvan Kakavand

Tarbiat Modares University

\section{Babak Shahbaz}

Tehran University of Medical Sciences 


\section{Vahdat Poortahmasebi}

Tabriz University of Medical Sciences

\section{Sara Akhavan Rezayat}

Tehran University of Medical Sciences

\section{Mohammad Reza Karimi}

Tehran University of Medical Sciences

\section{Ali Jafarpour}

Tehran University of Medical Sciences

\section{Saber Soltani}

Tehran University of Medical Sciences

\section{Azam Ghaziasadi}

Tehran University of Medical Sciences

\section{Razieh Dowran}

Tehran University of Medical Sciences

\section{Shohreh Azimi}

Tehran University of Medical Sciences

\section{Shima Sadeghipour Marvi}

Tehran University of Medical Sciences

\section{Foad Abazari}

Tehran University of Medical Sciences

\section{Milad Zandi}

Tehran University of Medical Sciences

\section{Delaram Yaghoobzadeh}

Tehran University of Medical Sciences

\section{Seyed Mohammad Jazayeri}

Tehran University of Medical Sciences

\section{Ahmad Tavakoli ( $\sim$ Tavakoli.a@iums.ac.ir)}

Iran University of Medical Sciences

\section{Research Article}

Keywords: SARS-CoV-2, COVID-19, Pediatric, Intensive care unit, ICU

Posted Date: March 23rd, 2021

DOI: https://doi.org/10.21203/rs.3.rs-326352/v1

License: (c) (i) This work is licensed under a Creative Commons Attribution 4.0 International License. Read Full License 
Version of Record: A version of this preprint was published at Frontiers in Emergency Medicine on July 11th, 2021. See the published version at https://doi.org/10.18502/fem.v5i4.6692. 


\section{Abstract}

Background: To date, less is known about the clinical features of COVID-19 pediatric patients admitting to ICUs. Herein, we aimed to describe the differences in demographic characteristics, laboratory findings, clinical presentations, and outcomes between COVID-19 pediatric patients admitting to ICU and non-ICU settings.

Methods: This multicenter study involved 15 general and pediatrics hospitals on confirmed severe acute respiratory syndrome coronavirus 2 (SARS-CoV-2) infection by positive real-time reverse transcription polymerase chain reaction (RT-PCR) between March 19 and May 31, 2020, during the initial peak of the COVID-19 pandemic in Iran.

Results: Overall, 166 patients were included, of which 61 (36.7\%) required ICU admission, especially in $<5$ years old age group. Malignancy and heart diseases were the most frequent underlying condition. There was significant decrease in platelet counts, $\mathrm{PH}, \mathrm{HCO}$ and base excess as well as increases in creatinine, creatine phosphokinase and potassium levels between ICU-admitted and non-ICU patients. Dyspnea was the major symptom for ICU group patients. Acute respiratory distress syndrome (ARDS), shock and acute cardiac injury were the most common features among ICU-admitted patients. The mortality rate was substantially higher in the ICU than in non-ICU patients ( $45.9 \%$ vs. $1.9 \%$, respectively; $P<0.001)$.

Conclusions: Underlying diseases were the major contributing factors in COVID-19 pediatric patients for the increased ICU admissions and mortality rates. There are few paraclinical parameters for differentiating pediatrics in terms of prognosis and serious outcomes of COVID-19. Healthcare providers should consider children as a high-risk group, especially those with younger age and underlying medical conditions and define strategies to control and prevent COVID-19 transmission in this population.

\section{Background}

The current Coronavirus Disease 2019 (COVID-19) pandemic caused by the severe acute respiratory syndrome coronavirus 2 (SARS-CoV-2) generally causes mild to moderate respiratory tract diseases in humans, and patients usually recover without any special treatment. However, older people and especially those with underlying medical conditions are at an increased risk of developing severe disease outcomes [1].

Several studies on COVID-19 infection among pediatric patients have revealed differences in clinical signs and symptoms, prevalence rates, and mortality rates compared to adults [2,3]. Children are less affected than older individuals by SARS-CoV-2 in the aspect of the number of infected persons and the incidence of serious adverse outcomes [4, 5]. Based on the results of previous epidemiological investigations, the prevalence of children affected by COVID-19 was $2.2 \%$ and $1.7 \%$ in China and the USA, respectively $[3,6]$. SARS-CoV-2 is transmitted among the pediatric population mainly through direct contact, contaminated droplets, and perhaps aerosols [7, 8]. 
Like adults, children can also experience a severe form of COVID-19 infection, leading to intensive care unit (ICU) admission. In previous studies, the ICU admission rate among children with COVID-19 varied from 1.7-16\% [9-12]. However, the rate is lower than those reported for adults (ranged from 5-32\%) [13-17]. To date, limited studies have been carried out to characterize the clinical, laboratory, and demographic features of pediatric COVID-19 patients in Iran [18-21]. Among four studies reporting epidemiological and clinical data of pediatric patients with COVID-19 infection, the largest sample size was 35 cases in the survey conducted by Mahmoudi et al. [19].

Herein, we aimed to conduct a large multicenter study to compare demographic characteristics, laboratory findings, clinical features, and outcomes between pediatric COVID-19 patients admitted to the ICU versus non-ICU cases.

\section{Methods}

\section{Study design, setting, and participants}

The current survey was a retrospective cross-sectional study carried on a total of 325 pediatric patients diagnosed with COVID-19 infection who admitted to 15 general and pediatrics hospitals collaborative to the Iranian Network for Research in Viral Diseases (INRVD) between March 19th and May 31th 2020. Overall results have been submitted elsewhere (under revision). A proportion of this population in whom COVID-19 was confirmed by positive real-time reverse transcription polymerase chain reaction (RT-PCR) for SARS-CoV-2, according to WHO interim guidance [22] was selected for further analysis $(n=166)$. The major inclusion criteria were patients who needed ventilation support either invasive mechanical ventilation or extra corporeal membrane oxygenation (ECMO) and/or organ dysfunction development who were transferred into the ICU. All other patients were transferred to wards for specialist care and were included as non-ICU cases. This study was approved by the Institutional Review Board of Tehran University of Medical Sciences (Ethics code number: 1399.378) and was conducted in compliance with the principles of the Declaration of Helsinki. Written informed consent was obtained from parents of pediatric patients.

\section{Molecular Detection Of SARS-CoV-2}

Throat and nasal samples were obtained using flocked swabs immediately after admission. Laboratory confirmation of the SARS-CoV-2 was performed using the RT-PCR assay [22]. RT-PCR was carried out using the diagnostic kits approved by the Iranian Pasture Institute, targeting the $E$ and RdP genes, along with the same protocol for all laboratories across the country. The samples were deemed positive if the cycle thresholds (Ct) value was $\leq 37$ and negative if the $\mathrm{Ct}$ value was $>40$. Samples with a $\mathrm{Ct}$ value between 37-40 was considered as a borderline result and were repeated.

\section{Laboratory And Imaging Indicators}

Laboratory examinations including routine blood tests, hematological, biochemical tests and assessment of biomarkers for monitoring lung, liver, and renal functions along with blood saturation parameters were 
performed in hospitals' laboratories. According to the guidelines issued by The Ministry of Health, all COVID-19 confirmed cases with any respiratory symptoms underwent a chest $\mathrm{X}$-ray upon admission. A chest CT scan usually applied in the case of either the presence of any abnormality in their X-ray or for the patients who progress to the severe form of the disease.

\section{Data Collection}

The epidemiological and demographic data, comorbidity, clinical symptoms, and signs on the admission of all laboratory-confirmed COVID-19 pediatric patients were retrospectively extracted from electronic medical records, according to predefined standardized data collection forms provided by INRVD.

\section{Statistical analysis}

Statistical analyses were performed using R software (R Foundation for Statistical Computing, Vienna, Austria; http://cran.r-project.org/). Continuous variables were presented as medians and interquartile ranges (IQR), and categorical variables were expressed as counts (\%). Fisher's exact test and chi-square test of independence were used to compare categorical variables, and Wilcoxon's rank-sum test was used for continuous variables. For comparative analyses, a $P$-value less than 0.05 was considered statistically significant.

\section{Results}

\section{Demographic characteristics and associated comorbidities}

Table 1 presents demographic characteristics and related comorbidities of pediatric patients with COVID19 at hospital admission. Out of 166, 61 (36.7\%) were admitted in ICU, and 105 (63.3\%) were non-ICU cases. According to the age group, the highest and the lowest numbers of admitted cases to ICU were in the age group of $1-5$ and $5-10$ years, respectively ( $31.1 \%$ vs $14.7 \%, P=0.02$, Table 1$)$. Males were more infected in both ICU and non-ICU settings compared to the females $(62.8 \%$ vs $37.1 \%$ and $59.0 \%$ vs $40.9 \%$, respectively, $P=0.7$, Table 1 ). Malignancies and heart were the most common underlying conditions; each affecting $11.4 \%$ of ICU-admitted patients (Table 1). $21.3 \%$ of ICU-admitted patients and $39.0 \%$ of non-ICU patients had histories of antibiotic use $(P=0.02$, Table 1$)$. However, there were no significant differences in influenza vaccination history, corticosteroid therapy, and chemotherapies between two groups (Table 1). 
Table 1

Demographic characteristics and associated comorbidities of pediatric patients with COVID-19

\begin{tabular}{|c|c|c|c|c|}
\hline Admission detail & Overall $(N=166)$ & Non-ICU $(\mathrm{N}=105)$ & $\operatorname{ICU}(\mathrm{N}=61)$ & $P$ value \\
\hline \multicolumn{4}{|l|}{ Age group (Year), No. (\%) } & \multirow[t]{5}{*}{$0.02^{*}$} \\
\hline $0-1$ & $28(16.8)$ & $11(10.4 \%)$ & $17(27.8 \%)$ & \\
\hline $1-5$ & $53(31.9 \%)$ & $34(32.3 \%)$ & $19(31.1 \%)$ & \\
\hline $5-10$ & $26(15.6 \%)$ & $17(16.3 \%)$ & $9(14.7 \%)$ & \\
\hline $10-15$ & $56(33.7 \%)$ & $41(39.0 \%)$ & $15(24.5 \%)$ & \\
\hline \multicolumn{4}{|l|}{ Gender, No. (\%) } & \multirow[t]{3}{*}{0.7} \\
\hline Male & $102(61.4 \%)$ & $66(62.8 \%)$ & $36(59.0 \%)$ & \\
\hline Female & $64(38.5 \%)$ & $39(37.1 \%)$ & $25(40.9 \%)$ & \\
\hline \multicolumn{5}{|l|}{ Associated comorbidities, No. (\%) } \\
\hline Asthma & $4(2.4 \%)$ & $3(2.8 \%)$ & $1(1.6 \%)$ & \multirow[t]{10}{*}{$<0.001^{*}$} \\
\hline Cystic fibrosis & $1(0.6 \%)$ & $1(0.9 \%)$ & $0(0 \%)$ & \\
\hline Chronic kidney disease & $4(2.4 \%)$ & $1(0.9 \%)$ & $3(4.9 \%)$ & \\
\hline Diabetes & $1(0.6 \%)$ & $1(0.9 \%)$ & $0(0 \%)$ & \\
\hline Failure to thrive & $4(2.4 \%)$ & $2(1.9 \%)$ & $2(3.2 \%)$ & \\
\hline Heart diseases & $9(5.4 \%)$ & $2(1.9 \%)$ & $7(11.4 \%)$ & \\
\hline Immune suppression & $2(1.2 \%)$ & $0(0 \%)$ & $2(3.2 \%)$ & \\
\hline Malignancy & $20(12.0 \%)$ & $13(12.3 \%)$ & $7(11.4 \%)$ & \\
\hline Other & $24(14.4 \%)$ & $7(6.6 \%)$ & $17(27.8 \%)$ & \\
\hline No comorbidity & $97(58.4 \%)$ & $75(71.4 \%)$ & $22(36.0 \%)$ & \\
\hline \multicolumn{5}{|l|}{ Patient history, No. (\%) } \\
\hline History of antibiotic use & $54(32.5 \%)$ & $41(39.0 \%)$ & $13(21.3 \%)$ & $0.02^{\star}$ \\
\hline History of flu vaccination & $22(13.2 \%)$ & $13(12.3 \%)$ & $9(14.7 \%)$ & 0.8 \\
\hline History of corticosteroid therapy & $16(9.6 \%)$ & $9(8.5 \%)$ & $7(11.4 \%)$ & 0.7 \\
\hline History of chemotherapy & $15(9.0 \%)$ & $9(8.5 \%)$ & $6(9.8 \%)$ & 0.9 \\
\hline
\end{tabular}

\section{Clinical Characteristics}


Fever and cough were the most frequent clinical symptoms among both groups. However, dyspnea was more prevalent among the ICU than non-ICU cases (50.8\% vs $26.6 \%$, respectively, $P=0.003$, Table 1 ).

Signs such as grunting and nasal flaring were seen more frequently in ICU versus non-ICU patients (0.01 and $<0.001$, respectively, Table 2). 
Table 2

Clinical characteristics and outcomes of pediatric patients with COVID-19

\begin{tabular}{|c|c|c|c|c|}
\hline Admission Detail & $\begin{array}{l}\text { Overall }(\mathrm{N}= \\
166)\end{array}$ & $\begin{array}{l}\text { Non-ICU }(\mathrm{N}= \\
105)\end{array}$ & ${ }_{61)}^{\operatorname{ICU}}(\mathrm{N}=$ & $P$ value \\
\hline \multicolumn{5}{|l|}{ Symptoms, No. (\%) } \\
\hline Fever & $122(73.4 \%)$ & $81(77.1 \%)$ & $41(67.2 \%)$ & 0.2 \\
\hline Fatigue & $27(16.2 \%)$ & $19(18.0 \%)$ & $8(13.1 \%)$ & 0.5 \\
\hline Cough & $89(53.6 \%)$ & $59(56.1 \%)$ & $30(49.1 \%)$ & 0.5 \\
\hline Anorexia & $42(25.3 \%)$ & $26(24.7 \%)$ & $16(26.2 \%)$ & 0.9 \\
\hline Dyspnea & $59(35.5 \%)$ & $28(26.6 \%)$ & $31(50.8 \%)$ & $0.003^{*}$ \\
\hline Sore throat & $7(4.2 \%)$ & $6(5.7 \%)$ & $1(1.6 \%)$ & 0.4 \\
\hline Diarrhea & $30(18.0 \%)$ & $18(17.1 \%)$ & $12(19.6 \%)$ & 0.8 \\
\hline Nausea/Vomiting & $55(33.1 \%)$ & $37(35.2 \%)$ & $18(29.5 \%)$ & 0.6 \\
\hline Headache & $10(6.0 \%)$ & $10(9.5 \%)$ & $0(0 \%)$ & $0.01 *$ \\
\hline Abdominal pain & $9(5.4 \%)$ & $7(6.6 \%)$ & $2(3.2 \%)$ & 0.5 \\
\hline Myalgia & $3(1.8 \%)$ & $3(2.8 \%)$ & $0(0 \%)$ & 0.3 \\
\hline Rhinorrhea & $3(1.8 \%)$ & $2(1.9 \%)$ & $1(1.6 \%)$ & 0.9 \\
\hline $\begin{array}{l}\text { Drowsiness/Loss of } \\
\text { consciousness }\end{array}$ & $9(5.4 \%)$ & $2(1.9 \%)$ & $7(11.4 \%)$ & 0.01 \\
\hline Seizures & $11(6.6 \%)$ & $4(3.8 \%)$ & $7(11.4 \%)$ & 0.1 \\
\hline Skin rash & $6(3.6 \%)$ & $4(3.8 \%)$ & $2(3.2 \%)$ & 0.9 \\
\hline \multicolumn{5}{|l|}{ Clinical signs, No. (\%) } \\
\hline Cyanosis & $7(4.2 \%)$ & $2(1.9 \%)$ & $5(8.1 \%)$ & 0.1 \\
\hline Grunting & $9(5.4 \%)$ & $2(1.9 \%)$ & $7(11.4 \%)$ & $0.01 *$ \\
\hline Nasal flaring & $19(11.4 \%)$ & $3(2.8 \%)$ & $16(26.2 \%)$ & $<.001 *$ \\
\hline Wheezing & $18(10.8 \%)$ & $9(8.8 \%)$ & $9(14.7 \%)$ & 0.3 \\
\hline Respiratory fine crackles & $30(18.0 \%)$ & $15(14.2 \%)$ & $15(24.5 \%)$ & 0.1 \\
\hline Respiratory Coarse Crackles & $21(12.6 \%)$ & $12(11.4 \%)$ & $9(14.7 \%)$ & 0.7 \\
\hline Shock & $9(5.4 \%)$ & $3(2.8 \%)$ & $6(9.8 \%)$ & 0.07 \\
\hline Arrhythmia & $4(2.4 \%)$ & $1(0.9 \%)$ & $3(4.9 \%)$ & 0.1 \\
\hline
\end{tabular}




\begin{tabular}{|lllll|}
\hline Admission Detail & $\begin{array}{l}\text { Overall }(\mathbf{N}= \\
\mathbf{1 6 6})\end{array}$ & $\begin{array}{l}\text { Non-ICU }(\mathbf{N}= \\
\mathbf{1 0 5})\end{array}$ & $\begin{array}{l}\text { ICU }(\mathbf{N}= \\
\mathbf{6 1})\end{array}$ & $P$ value \\
\hline Acute kidney injury & $2(1.2 \%)$ & $0(0 \%)$ & $2(3.2 \%)$ & 0.1 \\
\hline $\begin{array}{l}\text { Acute respiratory distress } \\
\text { syndrome }\end{array}$ & $19(11.4 \%)$ & $2(1.9 \%)$ & $17(27.8 \%)$ & $<$ \\
\hline Acute cardiac injury & $4(2.4 \%)$ & $0(0 \%)$ & $4(6.5 \%)$ & 0.001 * \\
\hline Clinical outcome, No. (\%) & & & & \\
\hline Death & $30(18.1 \%)$ & $2(1.9 \%)$ & $28(45.9 \%)$ & $<$ \\
\hline Recovered & $136(81.9 \%)$ & $103(98.1 \%)$ & $33(54.1 \%)$ & 0.001 * \\
\hline
\end{tabular}

Among a list of complications, the acute respiratory distress syndrome (ARDS), shock and acute cardiac injury were the most common features among ICU-admitted patients compared to non-ICU patients with significant associations ( $P<0.001, P=0.07$ and $P=0.01$, respectively, Table 2$)$. The mortality rate was significantly higher in the ICU than in non-ICU patients ( $45.9 \%$ vs. $1.9 \%$, respectively; $P<0.001$, Table 2 ).

\section{Laboratory Data}

There were no substantial differences between both groups in terms of WBC counts, serum inflammatory indexes (CRP and ESR) and other hematological parameters (Table 3). Exceptionally, 19 (32\%) of patients admitted to the ICU had normal platelet counts compared to $46(51 \%)$ of those with non-ICU patients $(P=$ 0.08 , Table 3). Regarding biochemistry parameters, significant increases in creatinine, creatine phosphokinase (CPK) and LDH levels were observed in ICU compared to non-ICU admitted patients, $(P=$ $0.06,0.01$ and 0.06 , respectively, Table 3 ). An elevated level of potassium was seen in $25 \%$ and $6.9 \%$ of ICU and non-ICU admitted patients, respectively, while it was decreased in $7.0 \%$ and $2.3 \%$ of ICU-admitted and non-ICU patients, respectively $(P=0.002$, Table 3$)$. 
Table 3

Laboratory findings of pediatric patients with COVID-19

\begin{tabular}{|c|c|c|c|c|}
\hline & Overall $(N=166)$ & Non-ICU $(N=105)$ & $\operatorname{ICU}(\mathrm{N}=61)$ & $P$ value \\
\hline White blood cell & & & & 0.1 \\
\hline Decreased & $36(22 \%)$ & $27(27 \%)$ & $9(15 \%)$ & \\
\hline Increased & $23(14 \%)$ & $11(11 \%)$ & $12(20 \%)$ & \\
\hline Normal & $102(63 \%)$ & $63(62 \%)$ & $39(65 \%)$ & \\
\hline Neutrophil & & & & 0.1 \\
\hline Decreased & $19(12 \%)$ & $15(16 \%)$ & $4(7.1 \%)$ & \\
\hline Increased & $24(16 \%)$ & $12(12 \%)$ & $12(21 \%)$ & \\
\hline Normal & $109(72 \%)$ & 69 (72\%) & $40(71 \%)$ & \\
\hline Lymphocyte & & & & 0.1 \\
\hline Decreased & $52(34 \%)$ & $38(39 \%)$ & $14(25 \%)$ & \\
\hline Increased & $15(9.7 \%)$ & $11(11 \%)$ & $4(7.1 \%)$ & \\
\hline Normal & $87(56 \%)$ & $49(50 \%)$ & $38(68 \%)$ & \\
\hline Hemoglobin & & & & 0.2 \\
\hline Decreased & $68(44 \%)$ & $37(39 \%)$ & $31(53 \%)$ & \\
\hline Increased & $3(1.9 \%)$ & $2(2.1 \%)$ & $1(1.7 \%)$ & \\
\hline Normal & $83(54 \%)$ & 57 (59\%) & $26(45 \%)$ & \\
\hline Platelet & & & & 0.08 \\
\hline Decreased & $27(18 \%)$ & $15(16 \%)$ & $12(20 \%)$ & \\
\hline Increased & $58(39 \%)$ & $30(33 \%)$ & $28(47 \%)$ & \\
\hline Normal & $65(43 \%)$ & $46(51 \%)$ & $19(32 \%)$ & \\
\hline C-reactive protein & & & & 0.5 \\
\hline Increased & $34(72 \%)$ & $22(69 \%)$ & $12(80 \%)$ & \\
\hline Normal & $13(28 \%)$ & $10(31 \%)$ & $3(20 \%)$ & \\
\hline Erythrocyte sedimentation rate & & & & 0.3 \\
\hline Increased & $52(37 \%)$ & $36(40 \%)$ & $16(31 \%)$ & \\
\hline Normal & $89(63 \%)$ & $54(60 \%)$ & $35(69 \%)$ & \\
\hline
\end{tabular}




\begin{tabular}{|c|c|c|c|c|}
\hline & Overall $(N=166)$ & Non-ICU $(\mathrm{N}=105)$ & $\operatorname{ICU}(\mathrm{N}=61)$ & $P$ value \\
\hline Blood urea nitrogen & & & & 0.2 \\
\hline Increased & $35(23 \%)$ & $18(20 \%)$ & $17(28 \%)$ & \\
\hline Normal & $117(77 \%)$ & $74(80 \%)$ & $43(72 \%)$ & \\
\hline Creatinine & & & & 0.06 \\
\hline Increased & $70(46 \%)$ & $48(52 \%)$ & $22(37 \%)$ & \\
\hline Normal & $82(54 \%)$ & $44(48 \%)$ & $38(63 \%)$ & \\
\hline Sodium & & & & 0.1 \\
\hline Decreased & $13(9.0 \%)$ & $6(6.9 \%)$ & $7(12 \%)$ & \\
\hline Increased & $2(1.4 \%)$ & $0(0 \%)$ & $2(3.4 \%)$ & \\
\hline Normal & $130(90 \%)$ & $81(93 \%)$ & 49 (84\%) & \\
\hline Potassium & & & & $0.002^{\star}$ \\
\hline Decreased & $6(4.2 \%)$ & $2(2.3 \%)$ & $4(7.0 \%)$ & \\
\hline Increased & $20(14 \%)$ & $6(6.9 \%)$ & $14(25 \%)$ & \\
\hline Normal & $118(82 \%)$ & 79 (91\%) & $39(68 \%)$ & \\
\hline Prothrombin time & & & & 0.07 \\
\hline Decreased & $0(0 \%)$ & $0(0 \%)$ & $0(0 \%)$ & \\
\hline Increased & $17(35 \%)$ & $4(19 \%)$ & $13(46 \%)$ & \\
\hline Normal & $32(65 \%)$ & $17(81 \%)$ & $15(54 \%)$ & \\
\hline Partial thromboplastin time & & & & 0.5 \\
\hline Decreased & $21(43 \%)$ & $8(38 \%)$ & $13(46 \%)$ & \\
\hline Increased & $12(24 \%)$ & $7(33 \%)$ & $5(18 \%)$ & \\
\hline Normal & $16(33 \%)$ & $6(29 \%)$ & $10(36 \%)$ & \\
\hline International normalized ratio & & & & 0.08 \\
\hline Decreased & $0(0 \%)$ & $0(0 \%)$ & $0(0 \%)$ & \\
\hline Increased & $11(24 \%)$ & $2(10 \%)$ & $9(35 \%)$ & \\
\hline Normal & 35 (76\%) & $18(90 \%)$ & $17(65 \%)$ & \\
\hline Lactate dehydrogenase & & & & 0.06 \\
\hline Decreased & $2(2.3 \%)$ & $1(1.8 \%)$ & $1(3.1 \%)$ & \\
\hline
\end{tabular}




\begin{tabular}{|c|c|c|c|c|}
\hline & Overall $(\mathrm{N}=166)$ & Non-ICU $(\mathrm{N}=105)$ & $\operatorname{ICU}(\mathrm{N}=61)$ & $P$ value \\
\hline Increased & $57(65 \%)$ & $32(57 \%)$ & $25(78 \%)$ & \\
\hline Normal & $29(33 \%)$ & $23(41 \%)$ & $6(19 \%)$ & \\
\hline Creatine phosphokinase & & & & $0.01^{\star}$ \\
\hline Decreased & $0(0 \%)$ & $0(0 \%)$ & $0(0 \%)$ & \\
\hline Increased & $22(42 \%)$ & $9(27 \%)$ & $13(65 \%)$ & \\
\hline Normal & $31(58 \%)$ & $24(73 \%)$ & $7(35 \%)$ & \\
\hline Aspartate aminotransferase & & & & 0.8 \\
\hline Decreased & $0(0 \%)$ & $0(0 \%)$ & $0(0 \%)$ & \\
\hline Increased & $34(40 \%)$ & $19(38 \%)$ & $15(42 \%)$ & \\
\hline Normal & $52(60 \%)$ & $31(62 \%)$ & $21(58 \%)$ & \\
\hline Alanine aminotransferase & & & & 0.4 \\
\hline Decreased & $4(4.7 \%)$ & $2(4.1 \%)$ & $2(5.6 \%)$ & \\
\hline Increased & $21(25 \%)$ & $15(31 \%)$ & $6(17 \%)$ & \\
\hline Normal & $60(71 \%)$ & $32(65 \%)$ & $28(78 \%)$ & \\
\hline Alkaline phosphatase & & & & 0.9 \\
\hline Decreased & $4(44 \%)$ & $3(43 \%)$ & $1(50 \%)$ & \\
\hline Increased & $2(22 \%)$ & $2(29 \%)$ & $0(0 \%)$ & \\
\hline Normal & $3(33 \%)$ & $2(29 \%)$ & $1(50 \%)$ & \\
\hline D-dimer & & & & 0.9 \\
\hline Increased & $6(38 \%)$ & $3(38 \%)$ & $3(38 \%)$ & \\
\hline Normal & 10 (62\%) & $5(62 \%)$ & $5(62 \%)$ & \\
\hline Total Bilirubin & & & & 0.6 \\
\hline Increased & $4(27 \%)$ & $3(38 \%)$ & $1(14 \%)$ & \\
\hline Normal & 11 (73\%) & $5(62 \%)$ & $6(86 \%)$ & \\
\hline Calcium & & & & 0.3 \\
\hline Decreased & $26(47 \%)$ & 14 (54\%) & $12(41 \%)$ & \\
\hline Increased & $1(1.8 \%)$ & $1(3.8 \%)$ & $0(0 \%)$ & \\
\hline Normal & 28 (51\%) & $11(42 \%)$ & $17(59 \%)$ & \\
\hline
\end{tabular}




\begin{tabular}{|c|c|c|c|c|}
\hline & Overall $(\mathrm{N}=166)$ & Non-ICU $(\mathrm{N}=105)$ & $\operatorname{ICU}(\mathrm{N}=61)$ & $P$ value \\
\hline Phosphorus & & & & 0.9 \\
\hline Decreased & $2(67 \%)$ & $2(67 \%)$ & 0 (NA\%) & \\
\hline Increased & $1(33 \%)$ & $1(33 \%)$ & 0 (NA\%) & \\
\hline Normal & $0(0 \%)$ & $0(0 \%)$ & 0 (NA\%) & \\
\hline $\mathrm{pH}$ & & & & $0.002^{\star}$ \\
\hline Decreased & $41(50 \%)$ & $15(34 \%)$ & $26(68 \%)$ & \\
\hline Increased & $5(6.1 \%)$ & $5(11 \%)$ & $0(0 \%)$ & \\
\hline Normal & $36(44 \%)$ & $24(55 \%)$ & $12(32 \%)$ & \\
\hline PCo2 & & & & 0.6 \\
\hline Decreased & $35(43 \%)$ & $17(39 \%)$ & $18(49 \%)$ & \\
\hline Increased & $30(37 \%)$ & $18(41 \%)$ & $12(32 \%)$ & \\
\hline Normal & $16(20 \%)$ & $9(20 \%)$ & $7(19 \%)$ & \\
\hline $\mathrm{HCO} 3$ & & & & $<0.001$ * \\
\hline Decreased & $44(54 \%)$ & $16(36 \%)$ & $28(76 \%)$ & \\
\hline Increased & $7(8.6 \%)$ & $2(4.5 \%)$ & $5(14 \%)$ & \\
\hline Normal & $30(37 \%)$ & $26(59 \%)$ & $4(11 \%)$ & \\
\hline Po2 & & & & 0.5 \\
\hline Decreased & $48(62 \%)$ & $26(60 \%)$ & $22(63 \%)$ & \\
\hline Increased & $6(7.7 \%)$ & $2(4.7 \%)$ & $4(11 \%)$ & \\
\hline Normal & $24(31 \%)$ & $15(35 \%)$ & $9(26 \%)$ & \\
\hline Base excess & & & & 0.09 \\
\hline Decreased & $46(73 \%)$ & $23(64 \%)$ & $23(85 \%)$ & \\
\hline Increased & $8(13 \%)$ & $5(14 \%)$ & $3(11 \%)$ & \\
\hline Normal & $9(14 \%)$ & $8(22 \%)$ & $1(3.7 \%)$ & \\
\hline
\end{tabular}

\section{Blood Saturation Indexes}

In terms of blood saturation values, $\mathrm{PH}$ was decreased in $26(68 \%)$ of ICU patients compared with 15 (34\%) of non-ICU cases ( $P=0.002$, Table 3). Moreover, $\mathrm{HCo} 3$ was decreased in the former group 
compared with the latter group ( $76 \%$ and $36 \%$, respectively, Table 3). Lastly, Base Exess decrease observed in ICU (85\%) more than non-ICU groups (64\%) $(P=0.09$, Table 3$)$.

\section{Radiological Features}

The CT scan results performed on admission showed bilateral and unilateral ground glass opacity among $32 \%$ and $7.7 \%$ of non-ICU-admitted patients, respectively, and $25 \%$ and $6.8 \%$ of ICU admitted patients, respectively $(P=0.7)$. Bilateral and unilateral lung consolidation were also observed in $12 \%$ and $6.7 \%$ of non-ICU-admitted patients, respectively, and $21 \%$ and $12 \%$ of ICU admitted patients, respectively $(P=0.3)$. Bilateral and unilateral pleural effusion was found in $5.1 \%$ of non-ICU admitted patients, and $7 \%$ and $2.3 \%$ of ICU admitted patients, respectively $(P=0.8)$. In ICU admitted cases, unilateral and bilateral white lung were seen in $2.3 \%$ of cases and these findings were not observed in non-ICU cases $(P=0.2)$.

\section{Discussion}

Iran is considered one of the most affected countries by COVID-19 globally, with high incidence and mortality rates. To date, several studies have reported clinical parameters associated with COVID-19 infection in children; however, data on pediatric patients in Iran are still scarce. On the other hand, there are minimal published data on pediatric patients requiring ICU worldwide. This descriptive cross-sectional country-wide investigation compared the epidemiologic and clinical features of ICU admitted and nonadmitted pediatric patients with confirmed COVID-19 in Iran.

Present survey showed that malignancies and cardiac disorders were the most common underlying disease in ICU-admitted pediatric patients. Similar results were found in the surveys conducted by Shekerdemian et al. [23] and Alfraij et al.[24], where malignancy was the most frequent underlying disease among children with COVID-19 admitted to the ICU. Prata-Barbosa et al. and Alfraij et al. also reported that heart disease was amongst the most frequent comorbidities among COVID-19 pediatric patients admitted to the ICU $[24,25]$. According to these results, children with cancers and heart diseases were associated with increased risk of severe complications of COVID-19.

Investigators observed that COVID-19 patients with cancer had higher ICU admission rates, severe complications, invasive mechanical ventilation, and mortality rate compared with COVID-19 patients without cancer. The higher susceptibility of cancer patients to severe COVID-19 infection might be explained in part by their systemic immunocompromised status induced by the underlying malignancy and anticancer therapy. Furthermore, most childhood malignancies have aggressive behavior and require prolonged periods of intensive therapy, which are potentially associated with long-term side-effects such as severe impairment of innate and adaptive immunity [26-28]. On the other hand, some other studies suggested that children with cancer are not more susceptible to severe COVID-19 infection than other children [12, 28-31]. This controversy stems at least in part from the fact that different kinds of cancers have distinct clinical features such as different growth rates, different responses to treatment, and different prognoses. Unfortunately, we could not be able to find the data about the type of tumor in our 
patients due to the retrospective design of our study and so, further conclusions cannot be drawn at this stage.

A proportion of ICU admitted patients were children less than five years old. Similar findings were reported in two studies conducted by Dong et al. [2, 9], in which infants and younger children were more likely to develop severe clinical manifestations of COVID-19 infection compared with children higher than five years old. A potential explanation for this phenomenon might be the immaturity of the immune system. The immune system of neonates and young children is underdeveloped and subdued, which might render them more susceptible to most infections, including SARS-CoV-2.

Among different clinical symptoms, dyspnea was significantly frequent in pediatric patients admitted to ICU than the non-ICU patients. This finding was consistent with the result of a survey conducted in New York City [32]. As reported, dyspnea was the only clinical symptom, which was significantly more frequent in pediatric patients admitted to the ICU than those admitted to the medical wards $(92.3 \%$ vs. $30.3 \%$, respectively). Similar results were obtained in the study conducted by Bhumbra et al. [33], where $71 \%$ and $58 \%$ of COVID-19 pediatric patients admitted to the ICU and general ward presented dyspnea, respectively. Thus, it seems that in most cases, the severe form of COVID-19 in children is associated with lung involvement. This interpretation is supported by another finding: ARDS was substantially higher in patients admitted to the ICU (27.8\%) than those patients who were not admitted to the ICU $(1.9 \%)$. Moreover, Chao et al. reported that the rate of ARDS was higher in patients admitted to the ICU $(76.9 \%)$ compared with patients admitted to the medical unit (0\%) [32]. Present survey showed that acute cardiac injury and acute kidney injury cases were only seen among ICU patients. In parallel, Stewart et al. reported that most acute kidney injury cases (93\%) were found in those admitted to the pediatric ICU [34]. Chao et al. also showed a significantly higher rate of acute kidney injury among pediatric patients admitted to the ICU than non-ICU patients (38.5\% vs. $0 \%$, respectively) [32]. Alfraij et al. also reported that circulatory failure is significantly associated with pediatric death in their study cohort [24]. It has been reported that heart failure and acute cardiac injury are significantly associated with in-hospital death [35]. Taken together, these findings indicate that acute cardiac injury and acute kidney injury are associated with severe COVID-19 infection among children.

With exception of few blood test parameters abnormalities (such as decrease in platelet, increases in creatinine, LDH, CPK and potassium) and also some atypical blood saturation indexes, the difference in the rest of indexed were not substantial between ICU and non-ICU individuals. These findings shed important light on the nature of the disease in this population. Unlike in the adults, no significant laboratory parameters could be characterized for the prognosis of COVID-19 clinical outcomes in pediatrics worldwide.

\section{Conclusions}

In conclusion, this multicenter study demonstrates that underlying diseases were the major contributing factors in COVID-19 pediatric patients for the increased ICU admissions and mortality rates. There are few 
paraclinical parameters for differentiating pediatrics in terms of prognosis and serious outcomes of COVID-19. Our findings emphasize that healthcare providers should consider children as a high-risk group, especially those with younger age and underlying medical conditions and define strategies to control and prevent COVID-19 transmission in this population.

\section{List Of Abbreviations}

SARS-CoV-2: Severe acute respiratory syndrome coronavirus 2; ICU: Intensive care unit; RT-PCR: Reverse transcription polymerase chain reaction; ARDS: Acute respiratory distress syndrome; COVID-19: Coronavirus Disease 2019; INRVD: Iranian Network for Research in Viral Diseases; ECMO: Extra corporeal membrane oxygenation; IQR: Interquartile ranges; CRP: C-reactive protein; ESR: Erythrocyte sedimentation rate; CPK: Creatine phosphokinase; LDH: Lactate dehydrogenase;

\section{Declarations}

\section{Ethics approval and consent to participate}

The project was approved by the ethics committee of Tehran University of Medical Sciences (No. 1399.378) and followed the Declaration of Helsinki. Written consent was obtained from the guardians of the patients.

\section{Consent for publication}

Not applicable

\section{Availability of data and materials}

All data generated or analyzed during this study are included in this article.

\section{Competing interests}

The authors have no conflict of interest.

\section{Funding}

This study was financially supported by Iranian Ministry of Health, grants No: 160200-1056-554 and 160200-1057-436.

\section{Authors 'contributions}

Study inception and design: S.M.J, A.F, I.S; Data collation: A.F, N.P, M.K, M.R.S, H. H, Z.M, A.S.D, F.C, A.S, M.M, M.A, H.H, J.S, A.H, A.H, M.S.R, S.S, M.K, A.A, A.A, H.R.S, A.A.R, M.A, S.O.M, Z.S, A.S, V.P, D,Y; Statistical analysis: M.F; Drafting of the manuscript: A.T; Sorting data: P.K.A, F.N.M, S.M, R.K; Interpretation of data: 
B.S, A.T, S.A.R, M.R.K, A.J, S.S, A.G, R.D, S.A, S.S.M, F.A; Supervision: S.M.J, A.F, A.T; All authors have read and approved the manuscript.

\section{Acknowledgments}

Iranian Network for Research in Viral Diseases (INRVD) acknowledge the help of staff members of the collaborated hospitals including and virology student volunteers during the data entering phase of the study including: Mofid Children Hospital, Tehran; Nemazee Hospital, Shiraz; Imam Khomeini Hospital, Tehran; Aboozar Children' Hospital, Ahvaz; Be'sat Hospital, Hamadan; Taleqani Hospital, Arak; Be'sat Hospital, Sanandaj; Shahrivar Children's Hospital, Rasht; Ibn-Sina Hospital Sari; Ali Asghar Children's Hospital, Tehran; Children's Hospital, Tabriz; Shahid Rahimi Hospital of Khorramabad, Khorramabad; Masoumeh Children Hospital(Khorrami),Qom.

\section{References}

1. Sanyaolu A, Okorie C, Marinkovic A, Patidar R, Younis K, Desai P, Hosein Z, Padda I, Mangat J, Altaf $\mathrm{M}$ : Comorbidity and its Impact on Patients with COVID-19. SN comprehensive clinical medicine 2020:1-8.

2. Dong Y, Mo X, Hu Y, Qi X, Jiang F, Jiang Z, Tong S: Epidemiology of COVID-19 among children in China. Pediatrics 2020, 145(6).

3. Wu Z, McGoogan JM: Characteristics of and important lessons from the coronavirus disease 2019 (COVID-19) outbreak in China: summary of a report of 72314 cases from the Chinese Center for Disease Control and Prevention. Jama 2020, 323(13):1239-1242.

4. Colson P, Tissot-Dupont H, Morand A, Boschi C, Ninove L, Esteves-Vieira V, Gautret P, Brouqui P, Parola P, Lagier J-C: Children account for a small proportion of diagnoses of SARS-CoV-2 infection and do not exhibit greater viral loads than adults. European Journal of Clinical Microbiology \& Infectious Diseases 2020, 39(10):1983-1987.

5. Gaborieau L, Delestrain C, Bensaid P, Vizeneux A, Blanc P, Garraffo A, Georget E, Chalvon A, Garrec N, Laoudi Y: Epidemiology and clinical presentation of children hospitalized with SARS-CoV-2 infection in suburbs of Paris. Journal of Clinical Medicine 2020, 9(7):2227.

6. CDC COVID-19 Response Team. Coronavirus disease 2019 in children-United States, February 12April 2, 2020. MMWR Morb Mortal Wkly Rep. (2020) 69:422-6. doi: 10.15585/mmwr.mm6914e4.

7. Ovali F: Coronavirus-2019 Disease (COVID-19) in Children. Medeniyet medical journal 2020, 35(3):242.

8. Alsohime F, Temsah M-H, Al-Nemri AM, Somily AM, Al-Subaie S: COVID-19 infection prevalence in pediatric population: Etiology, clinical presentation, and outcome. Journal of infection and public health 2020.

9. Dong Y, Mo X, Hu Y, Qi X, Jiang F, Jiang Z, Tong S: Epidemiological characteristics of 2143 pediatric patients with 2019 coronavirus disease in China. Pediatrics 2020. 
10. Qiu H, Wu J, Hong L, Luo Y, Song Q, Chen D: Clinical and epidemiological features of 36 children with coronavirus disease 2019 (COVID-19) in Zhejiang, China: an observational cohort study. The Lancet Infectious Diseases 2020.

11. Tagarro A, Epalza C, Santos M, Sanz-Santaeufemia FJ, Otheo E, Moraleda C, Calvo C: Screening and severity of coronavirus disease 2019 (COVID-19) in children in Madrid, Spain. JAMA pediatrics 2020.

12. Lu X, Zhang L, Du H, Zhang J, Li YY, Qu J, Zhang W, Wang Y, Bao S, Li Y: SARS-CoV-2 infection in children. New England Journal of Medicine 2020, 382(17):1663-1665.

13. Huang C, Wang Y, Li X, Ren L, Zhao J, Hu Y, Zhang L, Fan G, Xu J, Gu X: Clinical features of patients infected with 2019 novel coronavirus in Wuhan, China. The lancet 2020, 395(10223):497-506.

14. Guan W-j, Ni Z-y, Hu Y, Liang W-h, Ou C-q, He J-x, Liu L, Shan H, Lei C-I, Hui DS: Clinical characteristics of coronavirus disease 2019 in China. New England journal of medicine 2020, 382(18):1708-1720.

15. Yang X, Yu Y, Xu J, Shu H, Liu H, Wu Y, Zhang L, Yu Z, Fang M, Yu T: Clinical course and outcomes of critically ill patients with SARS-CoV-2 pneumonia in Wuhan, China: a single-centered, retrospective, observational study. The Lancet Respiratory Medicine 2020.

16. Wang D, Hu B, Hu C, Zhu F, Liu X, Zhang J, Wang B, Xiang H, Cheng Z, Xiong Y: Clinical characteristics of 138 hospitalized patients with 2019 novel coronavirus-infected pneumonia in Wuhan, China. Jama 2020, 323(11):1061-1069.

17. Chen N, Zhou M, Dong X, Qu J, Gong F, Han Y, Qiu Y, Wang J, Liu Y, Wei Y: Epidemiological and clinical characteristics of 99 cases of 2019 novel coronavirus pneumonia in Wuhan, China: a descriptive study. The Lancet 2020, 395(10223):507-513.

18. Mamishi S, Heydari H, Aziz-Ahari A, Shokrollahi MR, Pourakbari B, Mahmoudi S, Movahedi Z: Novel coronavirus disease 2019 (COVID-19) outbreak in children in Iran: atypical CT manifestations and mortality risk of severe COVID-19 infection. Journal of Microbiology, Immunology and Infection 2020.

19. Mahmoudi S, Mehdizadeh M, Badv RS, Navaeian A, Pourakbari B, Rostamyan M, Ekbatani MS, Eshaghi H, Abdolsalehi MR, Alimadadi H: The coronavirus disease 2019 (COVID-19) in children: a study in an Iranian Children's Referral Hospital. Infection and Drug Resistance 2020, 13:2649.

20. Mohammadi A, Mohebbi I, Pirnejad H, Mirza-Aghazadeh J, Gharebaghi N, Ardakani AA, MirzaAghazadeh-Attari M: Clinical and radiological characteristics of pediatric patients with COVID-19: focus on imaging findings. Japanese Journal of Radiology 2020:1-6.

21. Soltani J, Sedighi I, Shalchi Z, Sami G, Moradveisi B, Nahidi S: Pediatric coronavirus disease 2019 (COVID-19): An insight from west of Iran. Northern Clinics of Istanbu/2020, 7(3):284.

22. World Health Organization (WHO). Laboratory testing for coronavirus disease 2019 (COVID-19) in suspected human cases: interim guidance, 2 March 2020. World Health Organization; 2020.

23. Shekerdemian LS, Mahmood NR, Wolfe KK, Riggs BJ, Ross CE, McKiernan CA, Heidemann SM, Kleinman LC, Sen Al, Hall MW: Characteristics and outcomes of children with coronavirus disease 2019 (COVID-19) infection admitted to US and Canadian pediatric intensive care units. JAMA pediatrics 2020. 
24. Alfraij A, Alamir AAB, Al-Otaibi AM, Alsharrah D, Aldaithan A, Kamel AM, Almutairi M, Alshammari S, Almazyad M, Macarambon JM: Characteristics and outcomes of coronavirus disease 2019 (COVID19) in criticallyill pediatric patients admitted to the intensive care unit: A multicenter retrospective cohort study. Journal of Infection and Public Health 2020.

25. Prata-Barbosa A, Lima-Setta F, Santos GRd, Lanziotti VS, Castro REVd, Souza DCd, Raymundo CE, Oliveira FRCd, Lima LFPd, Tonial CT: Pediatric patients with COVID-19 admitted to intensive care units in Brazil: a prospective multicenter study. Jornal de pediatria 2020, 96(5):582-592.

26. Kotecha RS: Challenges posed by COVID-19 to children with cancer. The Lancet Oncology 2020, 21(5):e235.

27. Tawbi H: A promising start for checkpoint inhibitors in childhood malignancies. The Lancet Oncology 2020, 21(1):13.

28. Cesaro S, Compagno F, Zama D, Meneghello L, Giurici N, Soncini E, Onofrillo D, Mercolini F, Mura R, Perruccio K: Screening for SARS-CoV-2 infection in pediatric oncology patients during the epidemic peak in Italy. Pediatric blood \& cancer 2020, 67(8).

29. Boulad F, Kamboj M, Bouvier N, Mauguen A, Kung AL: COVID-19 in Children With Cancer in New York City. JAMA oncology 2020.

30. Hrusak O, Kalina T, Wolf J, Balduzzi A, Provenzi M, Rizzari C, Rives S, del Pozo Carlavilla M, Alonso MEV, Pinilla ND: Flash survey on SARS-CoV-2 infections in pediatric patients on anti-cancer treatment. European Journal of Cancer 2020.

31. Bisogno G, Provenzi M, Zama D, Tondo A, Meazza C, Colombini A, Galaverna F, Compagno F, Carraro F, De Santis R: Clinical Characteristics and Outcome of Severe Acute Respiratory Syndrome Coronavirus 2 Infection in Italian Pediatric Oncology Patients: A Study From the Infectious Diseases Working Group of the Associazione Italiana di Oncologia e Ematologia Pediatrica. Journal of the Pediatric Infectious Diseases Society 2020, 9(5):530-534.

32. Chao JY, Derespina KR, Herold BC, Goldman DL, Aldrich M, Weingarten J, Ushay HM, Cabana MD, Medar SS: Clinical characteristics and outcomes of hospitalized and critically ill children and adolescents with coronavirus disease 2019 (COVID-19) at a Tertiary Care Medical Center in New York City. The Journal of Pediatrics 2020.

33. Bhumbra S, Malin S, Kirkpatrick L, Khaitan A, John CC, Rowan CM, Enane LA: Clinical features of critical coronavirus disease 2019 in children. Pediatric Critical Care Medicine 2020, 21(10):e948.

34. Stewart DJ, Hartley JC, Johnson M, Marks SD, du Pré P, Stojanovic J: Renal dysfunction in hospitalised children with COVID-19. The Lancet Child \& Adolescent Health 2020, 4(8):e28-e29.

35. Zhou F, Yu T, Du R, Fan G, Liu Y, Liu Z, Xiang J, Wang Y, Song B, Gu X: Clinical course and risk factors for mortality of adult inpatients with COVID-19 in Wuhan, China: a retrospective cohort study. The lancet 2020, 395(10229):1054-1062. 